\title{
ATIVIDADE PRÁTICA NO EAD ATRAVÉS DE LABORATÓRIO VIRTUAL: UMA ANÁLISE EXPLORATÓRIA NA DISCIPLINA DE FÍSICA MECÂNICA
}

\author{
CURITIBA, PARANA, BRASIL/PR JULHO/2018
}

\author{
Cristiane Adriana Ripka - UNINTER - cristiane.ri@uninter.com \\ Kellen Coelho dos Santos - UNINTER - kellen.s@uninter.com \\ Jessika Alvares Coppi Arruda Gayer - UNINTER - jessika.c@uninter.com \\ Tipo: Relato de Experiência Inovadora (EI) \\ Categoria: Métodos e Tecnologias \\ Setor Educacional: EDUCAÇÃO SUPERIOR
}

\begin{abstract}
RESUMO
Há impacto na inserção de uma interface interativa na disciplina de física mecânica, a partir da comparação de notas entre turmas do EaD? Esta foi a pergunta de pesquisa que motivou este estudo. $O$ artigo teve como objetivo mostrar se a utilização do laboratório virtual impactou no desempenho nas avaliações na disciplina básica de física mecânica. A pesquisa pode ser classificada como exploratória, pois o intuito era verificar os dados, de acordo com o problema de pesquisa proposto. A partir do curso de engenharia de produção, disciplina de física mecânica, as turmas escolhidas foram: turma $A$ período de 18/05/2015 a 29/06/2015 e turma $B$ - período de 05/09/2016 a 17/10/2018. Os dados obtidos foram da prova discursiva, teve um aumento de $33,08 \%$ na turma B, nota de 90 a 100 , em comparação com a turma $A$, e a prova objetiva, com redução de $33,41 \%$ na turma $B$, também na nota de 90 a 100, em comparação com a turma A. Evidenciou-se que a utilização do laboratório virtual não foi uma variável impactante na redução ou ascensão da nota.
\end{abstract}

Palavras-chave: Laboratórios EaD. Engenharia. Mediação EaD. 


\section{INTRODUÇÃo}

Quando se fala em um curso mais técnico no EaD, com o conhecimento específico, denso e com a necessidade de equilibrar a prática com a teoria, a sociedade, em seu senso comum, tende a rejeitar a ideia por acreditar que as atividades práticas não podem ser realizadas através do computador e assim, engana-se quem toma este cenário como verdade. Atualmente, as IES e empresas de tecnologia de informação investem, cada vez mais, em interfaces para trazer a realidade ao aluno do EaD.

De fato, o EaD teve uma expansão nos últimos anos que demandou uma grande estrutura tecnológica. Desta maneira, OLIVEIRA diz sobre as transformações no ensino a distância e o desafio dos profissionais quanto à esta expansão:

\footnotetext{
As mudanças e transformações que os novos dispositivos midiáticos impõem à linguagem são hoje tema de debates e discussões sobre a prática docente, esta agora às voltas com a urgente necessidade de dominar novos suportes tecnológicos que possam ser aplicados ao ensino e aprendizagem. Como se esse desafio por si só já não fosse enorme para os profissionais da linguagem e da educação, outro parece talvez ainda maior - o de compreender e também dominar - as novas nuances porque passa a linguagem a partir destes dispositivos (OLIVEIRA, 2012, p. 84).
}

Enfim, a pergunta que motivou este estudo foi: há impacto na inserção de uma interface interativa na disciplina de física mecânica, a partir de uma comparação de notas entre turmas do EaD? Este trabalho permitiu evidenciar se a utilização do laboratório virtual é ou não é uma variável que impacta na redução ou ascensão de notas.

Então, o objetivo do artigo é mostrar se a utilização do laboratório virtual impactou no desempenho nas avaliações na disciplina básica de física mecânica. A pesquisa pode ser classificada como exploratória, pois foi baseada em alinhar as convicções e intuições. O curso escolhido foi o de engenharia de produção e a disciplina de física geral, as turmas compreendem em turma A, período de 18/05/2015 a 29/06/2015 e turma $B$, período de 05/09/2016 a 17/10/2018, sabe-se que as duas turmas usaram o laboratório virtual.

A divisão do estudo se dá por: introdução, que apresenta a justificativa e objetivo do artigo; revisão bibliográfica, com a fundamentação teórica dos temas mediação pedagógica no EaD e processos de avaliativos no EaD; metodologia, que demonstra como os dados foram coletados e analisados; discussões e resultados, com ilustrações gráficas e comentários; e as considerações finais, sendo a conclusão do estudo.

\section{REFERENCIAL TEÓRICO}




\subsection{Mediação da Aprendizagem no EaD}

Ao pesquisar a definição de mediação notou-se que este termo foi inserido ao vocabulário português em 1670 e sua definição é dada como o ato ou efeito de mediar, de servir entre as pessoas, com o intuito de diminuir a discordância (MEIER e GARCIA, 2007, p. 37).

Mediar pode variar a sua definição, conforme o contexto e utilização, como comenta Houaiss (2001, apud MEIER e GARCIA, 2007, p. 37). De acordo com a filosofia mediar é um processo criativo com um termo inicial e um termo final, já para a psicologia, mediar é uma sequência de elos, estímulos e respostas, e também com uma motivação inicial e final do ciclo (MEIER e GARCIA, 2007, p. 37).

Sob o mesmo ponto de vista, Costa e Vallin (2014), a mediação pedagógica pode ser descrita como um incentivo ao pensar e é oportuno à aprendizagem. Assim, é uma forma de mostrar o conteúdo e proporcionar uma interação com os alunos, sendo uma interação com o material ou o professor.

A mediação é como uma ponte, pois estabelece uma conexão com o conhecimento atual e o que ele irá adquirir. Então, estimular o aluno a buscar fontes de conhecimento e fazer com que ele entenda que pode contestar os conceitos, proporciona a associação entre o conhecimento empírico com o conhecimento novo e assim, faz com que o aprendizado tenha sentido na vida (COSTA e VALLIN, 2014).

Logo após o avanço da internet, houve o desenvolvimento de ferramentas tecnológicas que modificaram a maneira de se comunicar, socializar e perceber os elementos presentes ao redor do indivíduo, tal qual como a forma de partilhar as informações e aprender algo (CORCINI, MOSER e MEDEIROS, 2017, p. 263).

Tendo em vista que o cenário atual é de uma geração que vive no mundo digital, com uma acessibilidade e utilização da tecnologia de uma forma mais descomplicada e acessível, é importante considerar a capacitação do docente a ferramentas tecnológicas, já que o próprio docente pode se sentir convidativo a utilizar tais meios como alternativos em suas aulas (CORCINI, MOSER e MEDEIROS, 2017, p. 266).

\subsection{Processos Avaliativos no EaD}

Os processos avaliativos são necessários para selecionar e desenvolver os discentes, por isso deve-se tomar cuidado ao realizar este procedimento com um aluno. Por isso é 
fundamental buscar formas de avaliar o real conhecimento do educando e este resultado só é possível se tiver um bom planejamento, com os critérios seletivos já determinados (NEGRÃO e et al, 2012, p. 90). Assim como no presencial, o professor do EaD precisa desenvolver o plano de ensino da disciplina conforme a forma e estrutura da temática abordada (SCHEMIN e ALMEIDA, 2017, p. 14).

No ensino presencial, o professor avalia o conhecimento que o aluno adquiriu através de provas e atividades (sendo em grupo ou não). Já para o ensino a distância, o processo avaliativo é o mesmo, porém o que difere são as ferramentas utilizadas pelo docente (NEGRÃO e et al, 2012, p. 90).

Num curso de engenharia EaD é notório a necessidade de recursos interativos, como os simuladores virtuais. Como exemplos destas interfaces tem-se programas que simulam a montagem de uma placa com seus componentes eletrônicos e programas computacionais que auxiliam nos cálculos matemáticos, a partir da exibição de gráficos.

Portanto, transformar o ensino em algo dinâmico e criativo são ações que podem ser alcançadas com o emprego de ferramentas tecnológicas, além disso a utilização destes recursos impacta positivamente no aprendizado do aluno. Logo, promover o êxito do educando no EaD envolve um corpo de colaboradores que transformam o conhecimento escrito, em aulas ou materiais ágeis e versáteis.

\section{METODOLOGIA}

A pesquisa pode ser classificada como exploratória, pois é baseada em alinhar as convicções e intuições, em síntese, a pesquisa permite uma maior versatilidade, já que possibilita a ampliação dos aspectos a serem estudados (GIL, 2010, p. 27). Primeiramente, houve a determinação do período para a seleção do conteúdo, sendo entre 2007 a 2017, pois acredita-se que é um período com materiais novos e atualizados. Posteriormente, a procura pelo material foi realizada pelo portal Google Acadêmico e os termos utilizados na pesquisa foram: educação a distância, ensino de engenharia $\mathrm{EaD}$, mediação pedagógica $\mathrm{EaD}$ e avaliação $\mathrm{EaD}$. Os artigos mais pertinentes à pesquisa, foram selecionados, lidos e compilados. Deste modo, houve a estruturação do referencial teórico, embasando o estudo. Além dos artigos, houve uma pesquisa pela bibliográfica relacionada aos assuntos de aprendizagem e EaD.

Os dados obtidos são de uma IES, com o foco no EaD. A IES tem aproximadamente 500 polos de apoio que estão distribuídos pelo Brasil e com mais de 180 mil alunos. A escolha do curso limitou-se em engenharia de produção, pois entende-se que o estudo 
seria melhor aplicado numa turma pequena ao invés de estender para mais engenharias. A partir da disciplina de física mecânica, determinou-se as turmas que compreendem em turma A para o período de 18/05/2015 a 29/06/2015 e turma B para o período de 05/09/2016 a 17/10/2018. A o tempo de oferta das turmas é determinado pelo IES. Para o item resultados, houve uma comparação nas notas das provas discursivas e objetivas dos alunos, logo a análise se deu entre duas turmas que utilizaram o laboratório.

\section{DISCUSSÕES E RESULTADOS}

\subsection{Descrição da disciplina}

A disciplina escolhida foi de física mecânica, pois é uma matéria que utiliza o laboratório virtual, bem como, é base no ensino médio, porém os conceitos usados no curso são mais densos por ser de graduação. Assim, a disciplina aborda conceitos como: movimento retilíneo, movimento em duas e três dimensões, leis de Newton, trabalho e energia cinética, movimento linear, impulso e colisões, rotação de corpos rígidos. Sua importância se dá ao fato de que permite que o discente tenha um conhecimento sólido que será utilizado nas disciplinas futuras, como: resistência dos materiais, mecânica dos fluídos, componentes mecânicos e entre outros.

\subsection{Interface do programa e breve descrição da atividade prática}

O laboratório virtual simula situações que podem acontecer no laboratório físico, desta maneira, como qualquer procedimento em um laboratório físico, há um roteiro a ser seguido para que o aluno tenha sucesso na atividade. O laboratório virtual utilizado pela IES é de uma das maiores redes de educação e a sua sede é em Londres. A empresa desenvolvedora do programa disponibiliza para a IES senha, login e apelido, que serão repassados aos alunos. A partir da distribuição dos acessos, o aluno faz a instalação do programa para assim, iniciar as atividades. Por conseguinte, estas atividades estão num arquivo e são disponibilizadas pelo desenvolvedor do programa, deste modo, o professor responsável seleciona qual experimento é pertinente para o discente e distribui através de uma ferramenta especifica no AVA.

Após a orientação de qual experimento deve ser realizado, o discente deve abrir o programa, selecionar a atividade correspondente e, consequentemente, montar na bancada virtual todos os elementos necessários para realizar a atividade, isto conforme as instruções. Para que o aluno tenha êxito na atividade, deve-se realizar todas as ações descritas no manual e em seguida deve-se anotar os valores obtidos no ensaio, 
pois é necessário responder as perguntas existentes nesse.

Assim que o aluno realiza a experiência é necessário elaborar um relatório, que deverá ser entregue no tempo determinado, isto de acordo com o andamento da disciplina. Todas as orientações estão registradas no AVA e o canal de comunicação com o professor está sempre aberto, a fim de auxiliar e dar suporte ao aluno. A intenção é que o aluno seja capaz de associar a aula teórica e prática com os experimentos realizados, ou seja, o laboratório caracteriza o que o aluno assiste e lê no material disponibilizado.

\subsection{Análise das avaliações e notas}

Para a análise dos dados foram escolhidos dois critérios avaliativos, dentre os quatro disponibilizado pela IES, sendo a prova objetiva e a prova discursiva. No ano de 2016, a avaliação objetiva era composta por 10 questões e 4 alternativas (a, b, c e d), já a prova discursiva era elaborada por 5 questões dissertativas. O período selecionado para a análise foi entre 18/05/2015 a 29/06/2015 - turma A e 05/09/2016 a 17/10/2015 - turma B. A quantidade de alunos que realizaram as provas está descrita no quadro 1.

Quadro 1 - Quantidade de alunos por prova

\begin{tabular}{lcc}
\hline & Turma A & Turma B \\
\hline Prova objetiva & 231 & 136 \\
Prova discursiva & 276 & 128
\end{tabular}

Fonte: Autoras, 2018.

Antes de analisar os dados, é importante ter conhecimento de alguns pontos. O primeiro é que a IES utiliza como classificação cognitiva a taxonomia de Bloom. Segundo é que a configuração da prova é feita por questões fáceis, médias, difíceis, o quadro 2 mostra como cada prova era configurada.

Quadro 2 - Configuração das provas.

\begin{tabular}{lccc}
\hline & Fácil & Médio & Difícil \\
\hline Prova objetiva - Turma A & 10 & 0 & 0 \\
Prova objetiva - Turma B & 6 & 4 & 0 \\
Prova discursiva - Turma A & 5 & 0 & 0 \\
Prova discursiva - Turma B & 3 & 2 & 0
\end{tabular}

Fonte: Autoras, 2018. 
As avaliações são elaboradas com questões aleatórias, então o banco de exercícios era da seguinte maneira, conforme o quadro 3 :

Quadro 3- Quantidade de questões

\begin{tabular}{lc}
\hline & Total de questões \\
\hline Prova objetiva - Turma A & 46 \\
Prova objetiva - Turma B & 27 \\
Prova discursiva - Turma A & 20 \\
Prova discursiva - Turma B & 27
\end{tabular}

Fonte: Autoras, 2018

As notas foram retiradas do AVA da IES, assim eles sofreram um tratamento antes do desenvolvimento dos gráficos. Para o cálculo da porcentagem (\%), foi dividido a quantidade de alunos que alcançaram um determinado parâmetro de nota pela quantidade total de alunos e, assim, multiplicado por 100. Conforme a fórmula 1:

Fórmula 1 - Fórmula para encontrar a porcentagem.

$$
(\%)=\frac{V P N}{N A} \times 100
$$

Fonte: Autoras, 2018

Onde:

VPN = Quantidade de alunos que atingiram o intervalo da nota.

$N A=$ Quantidade total dos alunos que realizaram a prova.

A média para aprovação na instituição é de 70, caso o valor seja abaixo o aluno deverá realizar a prova exame. Assim, pode-se construir os gráficos. Para a prova discursiva, tem-se o gráfico 1, conforme apresentado abaixo: 


\section{Prova discursiva}

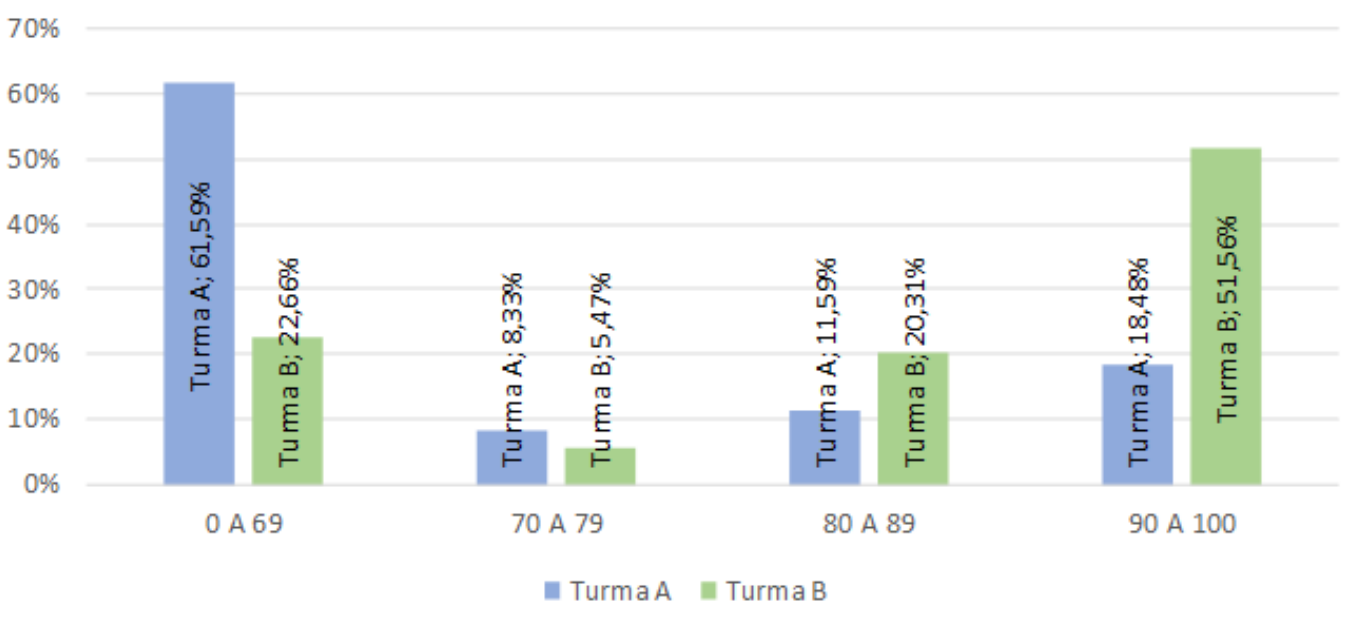

Gráfico 1 - Dados comparativos da prova discursiva. Fonte: Autoras, 2018.

A evolução das notas pode ser analisada da seguinte maneira:

0 a 69 - houve uma queda nas notas abaixo da média, com uma diferença de 38,94\%; 70 a 79 - redução de aproximadamente $3 \%$;

80 a 89 - houve um aumento de $8,72 \%$ na nota;

90 a 100 - um aumento de 33,08\% em relação a turma anterior.

Portanto, é possível verificar um aumento significativo na nota da prova discursiva. Este resultado satisfatório não é possível encontrar na prova objetiva. A evolução nesta modalidade de avaliação pode ser analisada da seguinte forma:

0 a 69 - um aumento de 19,92\% na nota classificada como abaixo da média;

70 a 79 - uma redução de $4,33 \%$ em relação a turma $A$;

80 a 89 - houve um aumento de 17,81\%;

90 a 100 - redução de $33,41 \%$.

Estes dados podem ser observados no gráfico 2: 


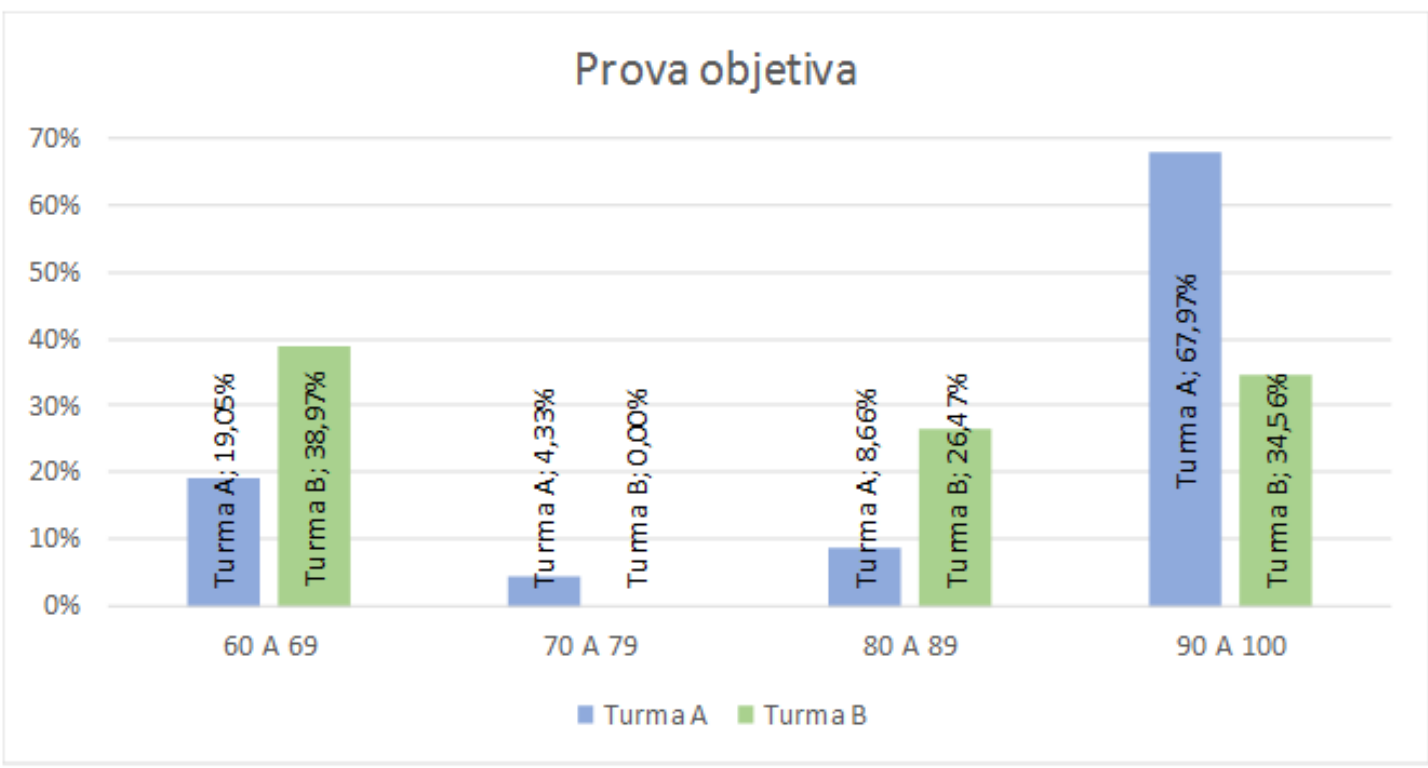

Gráfico 2 - Dados comparativos da prova objetiva.

Fonte: Autoras, 2018.

Assim, observa-se que a nota da prova discursiva teve uma variação positiva maior em comparação à variação da nota da prova objetiva. Logo, a prova discursiva teve um aumento de $16 \%$ na nota de 90 a 100, em comparação com a turma A e a prova objetiva teve um aumento de aproximadamente $20 \%$ na nota de 0 a 69 , em comparação com a turma B.

\section{CONSIDERAÇÕES FINAIS}

O intuito do estudo era de estratificar os dados de duas turmas, da disciplina de física mecânica, a fim de observar se a utilização do laboratório virtual impacta nas avaliações das disciplinas, a partir de uma comparação de notas das provas objetivas e discursivas.

Como a pesquisa tem caráter exploratório, verificou-se que a utilização do laboratório, para as turmas estudadas, não foi uma variável que impactou diretamente no desempenho das avaliações. Acredita-se que outras características podem ser as causadoras da ascensão ou declínio das notas, como: a inserção de cadernos de exercícios nas rotas, a diferença significativa da quantidade de alunos e até mesmo a composição da turma que apresenta indivíduos diferentes.

Como proposta para estudos futuros, indica-se verificar outras variáveis que possam justificar a diferença entre as notas. 
CORCINI, Luiz Fernando; SANTOS, Rodrigo Otávio dos; MOSER, Alvino. Fundamentos epistemológicos das aulas interativas (flipped classrooms): introduzindo o artigo de Marcel Lebrun. In: ALMEIDA, Siderly do C. D. de; MEDEIROS, Luciano Frontino de; MATTAR, João (orgs.). Educação e tecnologias: refletindo e transformando o cotidiano. São Paulo: Artesanato Educacional, 2017. p. 263 e 266.

COSTA, Júlio Resende; VALLIN, Celso. Pressupostos teóricos para a docência na EAD: reflexões preliminares acerca da mediação pedagógica. Revista Cientifica Internacional. Campos dos Goytacazes, vol. 1, n. 28, p 160 - 171, jan., 2014. Disponível em: . Acesso em: 29/08/2017.

GIL, Antônio Carlos. Como elaborar projetos de pesquisa. $5^{\mathfrak{a}}$ ed. São Paulo: Atlas, 2010. p. 27.

MEIER, Marcos; GARCIA, Sandra. Mediação da aprendizagem: contribuições de Feuerstein e de Vygotsky. Curitiba: Edição do autor, 2007. p. 37.

NEGRÃO, Keila Regina Mota; et al. Planejamento e avaliação em EaD: estudo de caso em um curso de graduação em administração. Revista do Centro de Ciências Exatas e Tecnologias. Belém, vol. 14, n. 30, p. 89 - 107, dez., 2012. Disponível em: . Acesso em: 25/08/2017.

OLIVEIRA, José Aparecido de. Desafios da Linguagem na Educação a Distância. Impulso, Piracicaba, vol. 22, n. 53, p. 83 - 91, jan/abr, 2012. Disponível em: < https://ww w.metodista.br/revistas/revistas-unimep/index.php/impulso/article/view/580/612>Acesso em: 28/06/2017.

SCHEMIN, Angela Cristina Cardozo; ALMEIDA, Siderly do C. D. de. Mediação pedagógica do professor-tutor em cursos na modalidade de educação a distância EAD. In: ALMEIDA, Siderly do C. D. de; MEDEIROS, Luciano Frontino de; MATTAR, João (orgs.). Educação e tecnologias: refletindo e transformando o cotidiano. São Paulo: Artesanato Educacional, 2017. p. 14. 